\title{
The use of oxybutynin for treating facial hyperhidrosis
}

\section{O uso da oxibutinina no tratamento da hiperidrose facial}

\author{
Nelson Wolosker ${ }^{1}$ \\ Paulo Kauffman ${ }^{3}$ \\ Samantha Neves ${ }^{5}$ \\ Pedro Puech-Leão
}

\author{
José Ribas Milanez de Campos ${ }^{2}$ \\ Marco Antonio Munia ${ }^{4}$ \\ Fábio Biscegli Jatene ${ }^{6}$
}

\begin{abstract}
BACKGROUND: Facial hyperhidrosis is a disease that may lead patients to serious emotional disturbances. Video-assisted thoracic sympathectomy provides excellent resolution of facial hyperhidrosis, but is associated with certain complications. The most frequent and important complication is compensatory hyperhidrosis. Especially in patients who have undergone resection of the second thoracic ganglion, the risk of severe compensatory hyperhidrosis is higher, which may cause dissatisfaction with the procedure.

OвJестіvE: The aim of this study was to evaluate the efficacy of the use of low doses of oxybutynin in treating facial hyperhidrosis as well as the level of patient satisfaction with its use.

METHODS: 25 patients with facial hyperhidrosis were treated with oxybutynin. The patients underwent 2 evaluations: before and after treatment. These evaluations were used to assess the patients' clinical improvement and quality of life.

RESULTS: We observed that more than $75 \%$ of the patients evolved with an improvement in facial hyperhidrosis, and $52 \%$ of them presented a great improvement.

CONCLUSION: Treatment of facial hyperhidrosis with oxybutynin is a good alternative to sympathectomy, since it presents good results and improves quality of life, in addition to not exposing patients to the risk of experiencing the side effects of sympathectomy.

Keywords: Advanced treatment; Clinical protocols; Hyperhidrosis; Indicators of quality of life; Sympathectomy; Sweating
\end{abstract}

Resumo: FundAmENTOS: Hiperidrose facial é uma doença que pode levar os pacientes a sérios distúrbios emocionais. A simpatectomia torácica vídeo-assistida proporciona excelente resolução da hiperidrose facial, mas está associada a algumas complicações, sendo a mais freqüente e mais importante a hiperidrose compensatória. Especialmente em pacientes submetidos à ressecção do segundo gânglio torácico, o risco de hiperidrose compensatória grave é maior, o que pode causar insatisfação com o procedimento.

Oвјетіvo: O objetivo deste estudo foi avaliar a eficácia e a satisfação dos pacientes com o uso da oxibutinina em doses baixas para tratar a hiperidrose facial em uma série grande de pacientes.

MÉTodos: 25 pacientes com hiperidrose facial foram tratados com oxibutinina. Os pacientes foram submetidos a duas avaliações: antes e depois do tratamento. Estas foram usadas para avaliar a melhoria clínica e a qualidade de vida.

Resultados: Observou-se que mais de 75\% dos pacientes evoluíram com melhora na hiperidrose facial, sendo que $52 \%$ deles apresentaram uma grande melhora.

CONCLUSÃO: O tratamento da hiperidrose facial com oxibutinina é uma boa alternativa à simpatectomia, visto que apresenta bons resultados e melhora a qualidade de vida, e os pacientes não correm o risco dos efeitos colaterais da simpatectomia.

Palavras-chave: Hiperidrose; Indicadores de qualidade de vida; Protocolos clínicos; Simpatectomia; Sudorese; Tratamento avançado

Recebido em 22.06.2010.

Aprovado pelo Conselho Consultivo e aceito para publicação em 20.07.2010.

* Work conducted at Clinics Hospital, College of Medicine of the University of Sao Paulo (HC -FMUSP) - Sao Paulo (SP), Brazil.

Conflito de interesse: Nenhum / Conflict of interest: None

Suporte financeiro: Nenhum / Financial funding: None

Associate professor, College of Medicine of the University of Sao Paulo (FMUSP) - Sao Paulo (SP), Brazil.

Staff Surgeon, Division of Thoracic Surgery, Clinics Hospital, College of Medicine of the University of Sao Paulo (HC -FMUSP) - Sao Paulo (SP), Brazil.

Assistant Professor, Division of Vascular Surgery, Clinics Hospital, College of Medicine of the University of Sao Paulo (HC -FMUSP) - Sao Paulo (SP), Brazil

$\mathrm{PhD}$ in Medicine, College of Medicine of the University of Sao Paulo (FMUSP). Medical researcher at the Division of Vascular Surgery, Clinics Hospital, College of Medicine of the University of Sao Paulo (HC - FMUSP) - Sao Paulo (SP), Brazil.

Medical researcher, Division of Vascular Surgery, Clinics Hospital, College of Medicine of the University of Sao Paulo (HC -FMUSP) - Sao Paulo (SP), Brazil.

Professor and Chairman, Division of Thoracic Surgery, Clinics Hospital, College of Medicine of the University of Sao Paulo (HC -FMUSP) - Sao Paulo (SP), Brazil.

Professor and Chairman, Division of Vascular Surgery, Clinics Hospital, College of Medicine of the University of Sao Paulo (HC -FMUSP) - Sao Paulo (SP), Brazil.

C 2011 by Anais Brasileiros de Dermatologia 


\section{INTRODUCTION}

Facial hyperhidrosis $(\mathrm{FH})$ is a disease that may lead patients to serious emotional disturbances. ${ }^{1}$ Local treatment and psychotherapy have low effectiveness. ${ }^{2}$ Video-assisted thoracic sympathectomy (VATS) provides excellent resolution of facial hyperhidrosis, but is associated with certain complications, especially with compensatory hyperhidrosis, which is the most frequent and important complication. ${ }^{3 \cdot 6}$ This occurs, to a mild degree, in most patients who have undergone the treatment of palmar or axillary hyperhidrosis. However, the risk is particularly higher in patients treated for FH who have been submitted to the resection of the second thoracic ganglion, which may cause dissatisfaction with the procedure. ${ }^{7-9}$

Different anticholinergic drugs were used to treat hyperhidrosis in the past, but their use did not become routine due to side effects. ${ }^{10}$

Oxybutynin is an anticholinergic drug that can be safely used at high doses (over $15 \mathrm{mg} /$ day) to treat patients with urological disorders related to micturition. ${ }^{11}$ An effect observed in such patients is diminished sudoresis. Its use for treating hyperhidrosis has only been described in three case reports on patients with hyperhidrosis and one series of 14 patients with compensatory hyperhidrosis. ${ }^{12-15}$ Daily practice has shown us that oxybutynin at low doses (up to 10 $\mathrm{mg}$ /day) seems to generate fewer side effects, while it is still effective to reduce sudoresis in patients with facial hyperhidrosis.

Considering that the main treatment for facial hyperhidrosis is botulinum toxin or surgical procedures (video-assisted thoracic sympathectomy), which are often accompanied by unpleasant side effects, oxybutynin provides a possible alternative for its treatment.

The aim of the present study was to evaluate the effectiveness of the use of oxybutynin at low doses for treating facial hyperhidrosis in a large series of patients as well as to evaluate patient satisfaction with the treatment.

\section{MATERIALS \& METHODS}

This was a non-randomized and uncontrolled study carried out in accordance with the ethical standards of the university's Committee of Ethics for Analysis of Research Projects on Human Experimentation. From January 2007 to June 2009, 25 consecutive patients with facial hyperhidrosis were treated with oxybutynin. Of these, six patients were lost to follow-up. Thus, data were collected from 19 patients who underwent clinical treatment. Patients with glaucoma were not treated.

All of the patients underwent similar treatment following the same protocol. During the first week, they received $2.5 \mathrm{mg}$ of oxybutynin once a day in the evening. From the eighth to the $42^{\text {nd }}$ day, they received $2.5 \mathrm{mg}$ twice a day, and from the $43^{\text {rd }}$ day to the end of the $12^{\text {th }}$ week, they received $5 \mathrm{mg}$ twice a day.

The patients were between 20 and 62 years old, with a mean of $41.8 \pm 14.0$ years and median of 43.0 years. The group was composed of 9 women and 10 men. The patients' body mass index (BMI) ranged from 22.6 to 36.7 , with a mean of $28.0 \pm 3.7$ and median of 27.0.

In addition to facial hyperhidrosis, all of them presented hyperhidrosis in other sites of the body: thoracic and abdominal hyperhidrosis was observed in 10 patients (40\%), palmar in $9(36 \%)$, axillary in 7 (28\%), and plantar in 5 (20\%).

All of the patients underwent 3 evaluations for the purpose of this study. The first evaluation was carried out before the medication treatment, the second after 6 weeks of treatment and the last after 12 weeks of treatment. These were used to assess (1) the patients' clinical improvement of facial hyperhidrosis and the improvement of hyperhidrosis in other sites of the body, as reported by the patients by means of a clinical questionnaire; and (2) their quality of life (QOL), using a clinical protocol for QOL which was administered at each visit. ${ }^{16,17}$

The patients completed the clinical improvement questionnaire according to their subjective perception of improvement of sudoresis. They evaluated it on a scale ranging from 0 to 10 , in a way that 0 represented no improvement and 10 represented absence of hyperhidrosis, based on their own estimates without any intervention or advice from the interviewer. The improvement was recorded as null when the score was 0 ; slight, when it was 1 to 4 ; moderate, when it was 5 to 7 ; or great, when it was 8 to 10 .

Quality of life before treatment was classified into five different satisfaction levels, calculated as the summed total score from the protocol (ranging from 20 to 100 ). When the total was greater than 84 , the QOL was considered very poor; from 68 to 83 , poor; from 52 to 67 , good; from 36 to 51 , very good; and from 20 to 35, excellent.

Improvement of QOL after treatment was also classified into 5 different evolution levels. When the total was greater than 84 , the QOL was considered much worse; from 68 to 83 , slightly worse; from 52 to 67 , the same; from 36 to 51, slightly better; and from 20 to 35 , much better.

The following parameters were studied: evolution of facial hyperhidrosis; evolution of hyperhidrosis in other sites of the body; evaluation of QOL before treatment; evaluation of improvement in QOL after treatment; analysis of the patients' evolution accor- 
ding to QOL levels before treatment; analysis of improvement in QOL according to gender, age, and BMI; and finally, any complications and side effects.

\section{Statistical analysis}

For categorical variables, the ${ }^{-2}$ or the Student $t$ test was used. These statistical tests were used for comparing gender, age, and BMI with satisfaction (QOL). The associations between improvement of QOL according to the levels observed before treatment were investigated using the McNemar test. The significance level considered for all tests was $P=0.05$.

\section{RESULTS}

As pointed out previously, 24\% of the patients were lost during follow-up. The results of the treatment related to facial hyperhidrosis are presented in table 1.

More than $75 \%$ of the patients evolved with an improvement in facial hyperhidrosis, and 52\% of them presented a great improvement.

The results of the treatment related to other sites of hyperhidrosis reported by the patients are presented in table 2 .

More than $80 \%$ of the patients showed improvements in all of the sites presenting hyperhidrosis. There were no cases of worsening in other sites of hyperhidrosis.

The distribution of QOL before and after treatment is presented in table 3 .

Before treatment, all of the patients presented poor or very poor QOL. The median was 0.81 ( \pm $0.10)$.

After treatment, most of the patients presented improvements (73.6\%). The median was 0.40 ( \pm $0.12)$.

The analysis on the evolution of QOL among the patients, according to the levels observed before treatment, is presented in table 4 .

The patients with poor QOL before treatment presented the same results as those with very poor QOL before treatment.

The analysis of the evolution of QOL according to the patients' gender, age, and BMI is presented in

TABLE 1: Evolution of facial hyperhidrosis with the use of oxybutynin

\begin{tabular}{lll}
\hline & Improvement & No. (\%) \\
\hline \multirow{2}{*}{ Facial hyperhidrosis } & Worse & $0(0.0)$ \\
& null & $1(5.2)$ \\
& slight & $3(15.8)$ \\
& moderate & $5(26.4)$ \\
& great & $10(52.6)$ \\
\hline
\end{tabular}

table 5 .

There were no statistical differences in patients' evolution in relation to gender, age, or BMI.

Certain side effects were observed during the treatment. Headache was presented by one patient (5.2\%) while using $5 \mathrm{mg}$ of oxybutynin per day and by one patient (5.2\%) while using $10 \mathrm{mg} /$ day. In both cases, the headache disappeared with the use of common analgesics. Urine retention was reported by one patient (5.2\%) while using $10 \mathrm{mg} /$ day. No bladder drainage or suspension of oxybutynin was necessary in this patient.

Dry mouth was the side effect most frequently reported and was reported by the majority of the patients (70.5\%).

Most of the patients presented some degree of dry mouth during the treatment. The frequency and intensity of this side effect increased with higher doses.

\section{DISCUSSION}

There has been an increasing demand for treatment of hyperhidrosis worldwide because of the excellent results obtained with sympathectomy in treating patients with this condition, the widespread publicity about this disease in the current media, and the great incidence of this condition. ${ }^{18}$

Differently from palmar hyperhidrosis, in which symptoms most frequently start in childhood, patients with facial hyperhidrosis start experiencing its symptoms in adulthood. ${ }^{19,20}$ For this reason, most patients that seek treatment are adults in their forties. There is no female predominance as seen in other sites of hyperhidrosis, probably because this type of excessive sweating has greater repercussions in men's daily lives than in women's. ${ }^{21}$

Patients using oxybutynin to treat urinary disorders take larger doses (15 mg/day) and may present more severe side effects (dry mouth, headache, and urine retention). ${ }^{22}$ However, we did not observe this with the low and progressive doses used in the present study. The clinical treatment used by our group is well standardized. We start the treatment with very low doses of oxybutynin $(2.5 \mathrm{mg} /$ day $)$ and progressively increase the dose up to $10 \mathrm{mg} /$ day. We use this protocol because patients with urinary disorders were instructed to start taking $5 \mathrm{mg}$ every 12 hours and presented greater severity of dry mouth right at the beginning of the treatment. This discomfort led some patients to abandon the treatment. Through empirical practice, we found out that the incidence of side effects was lower when starting with very low doses ( $2.5 \mathrm{mg} /$ day) and increasing them progressively (up to $10 \mathrm{mg} /$ day). Moreover, when such effects did occur, patients were able to adapt to them better. 
TABLE 2: Evolution of hyperhidrosis with the use of oxybutynin

\begin{tabular}{llllll}
\hline \multicolumn{5}{c}{ Improvement } \\
\hline Hyperhidrosis site & \multicolumn{5}{c}{ no. (\%) } \\
\cline { 2 - 6 } & null & slight & moderate & great & total \\
\hline Thoracic + abdominal & 0 & $1(10.0)$ & $8(80.0)$ & $1(10.0)$ & 10 \\
Palmar & 0 & $1(11.1)$ & $3(33.3)$ & $5(55.6)$ & 9 \\
Axillary & 0 & 0 & $5(71.4)$ & $2(28.6)$ & 7 \\
Plantar & 0 & $1(20.0)$ & $1(20.0)$ & $3(60.0)$ & 5 \\
\hline
\end{tabular}

Dry mouth was the most frequently observed side effect. Using $5 \mathrm{mg}$ of oxybutynin per day, 68.3 $\%$ of the patients either did not present dry mouth or presented it mildly, which encouraged the patients to proceed with the treatment. Using $10 \mathrm{mg}$ per day, this symptom increased but was well tolerated. None of the patients abandoned the treatment due to this side effect. Moreover, less frequent side effects such as slight headache and urine retention were not a reason for the patients to discontinue the treatment.

The patients who sought medical assistance presented great dissatisfaction regarding facial hyperhidrosis. The degree of degradation of their low QOL was measured in our study by means of a specific QOL questionnaire on hyperhidrosis that has been validated and used in several published studies. ${ }^{23}$

The degree to which hyperhidrosis worsens a patient's QOL depends not only on the severity of the condition but also on the patient's adaptation to it. ${ }^{24}$ Some individuals with less severe hyperhidrosis present very poor QOL, whereas patients with very severe hyperhidrosis may report that their QOL is not so poor, because they have adapted better to their condition. All of the patients treated in this sample presented poor or very poor QOL.

Basically all patients in good clinical condition, except those who present glaucoma, can be treated with oxybutynin. This includes obese patients (the

TABLE 3: Quality of life (QOL) before and after oxybutynin treatment

\begin{tabular}{lll}
\hline & $\begin{array}{l}\text { QOL before } \\
\text { treatment }\end{array}$ & $\begin{array}{l}\text { QOL after } \\
\text { treatment }\end{array}$ \\
\hline $0.20-0.35$ (excellent) & 0 & $7(36.8 \%)$ \\
$0.36-0.51$ (very good) & 0 & $7(36.8 \%)$ \\
$0.52-0.67$ (good) & 0 & $5(26.4 \%)$ \\
$0.68-0.83$ (poor) & $10(52.6 \%)$ & 0 \\
$0.84-1.00$ (very poor) & $9(47.4 \%)$ & 0 \\
\hline
\end{tabular}

patients in this study have a body mass index of 28). With surgery, such patients might present greater risk of developing compensatory hyperhidrosis, in addition to the surgical risk.

We did not use any objective measurement of sudoresis because this kind of method only produces data at a specific point in time. There are no methods that can measure hyperhidrosis over an entire day. For this reason, we asked the patients to grade their improvement on a scale from 0 to 10 for each of the sites presenting hyperhidrosis reported.

The results obtained for treating facial hyperhidrosis were satisfactory. However, a $24 \%$ loss of follow-up can be a study limitation, because a large number of losses like this may have caused a selection bias. Facial sudoresis decreased in more than $75 \%$ of the cases, and in $73.2 \%$ of the cases with regard to QOL. When surgery is performed, the results are even better, given that more than $95 \%$ of the patients become free from facial hyperhidrosis. On the other hand, sympathectomy may give rise to compensatory hyperhidrosis, i.e. an irreversible increase in sudoresis in other sites of the body. ${ }^{25}$ In the present sample, we found that almost all of the patients presented hyperhidrosis in other sites, predominantly in the thoracic, abdominal, palmar and plantar regions. With drug treatment, we found that there was a great improvement (more than $80 \%$ ) in all of the other sites presenting hyperhidrosis.

Table 4: Evolution of quality of life according to the levels before treatment

\begin{tabular}{lll}
\hline & After treatment \\
\hline $\begin{array}{l}\text { Much better and a } \\
\text { little better }\end{array}$ & The same & P value \\
\hline $6(60.0 \%)$ & $4(40.0 \%)$ & 0.3877 \\
$8(88.9 \%)$ & $1(11.1 \%)$ & \\
\hline
\end{tabular}

$P$ value obtained using the McNemar test $=$ 
TABLE 5: Evolution of quality of life (QOL) according to patients' gender, age and BMI

\begin{tabular}{lllll}
\hline Variable & Category & $\begin{array}{l}\text { QOL much better }+ \\
\text { slightly better Freq. } \\
\text { (\%) or measurement }\end{array}$ & $\begin{array}{l}\text { QOL the same } \\
\text { Freq. (\%) or } \\
\text { measurement }\end{array}$ & P value \\
\hline Gender & Female & $10(72.1)$ & $1(27.9)$ & $>0.111$ \\
& Male & $4(75.8)$ & $4(24.2)$ & \\
Age (years) & $\mathrm{N}$ & 14 & 5 & $0.6341 *$ \\
& Range & $20.5-62.6$ & $22.5-59.8$ & \\
& Median & 42.5 & 43.0 & \\
& Mean & 42.6 & 39.1 & $0.3470 *$ \\
SMI & Standard deviation & 13.5 & 15.0 & \\
& N & 14 & 5 & $23.7-30.5$ \\
& Range & $22.6-36.7$ & 26.8 & 27.0 \\
& Median & 28.4 & 2.4 & \\
& Mean & 28.9 & & \\
& Standard deviation & 4.1 & & \\
\hline
\end{tabular}

$P$ value obtained using the chi-square test

* P value obtained using the Student $t$ test

The prognostic factors currently associated with worsening of QOL following thoracic sympathectomy to treat hyperhidrosis are surgical failure and severe compensatory hyperhidrosis. ${ }^{26,27}$ On the other hand, with clinical treatment, we did not observe any worsening of QOL. In the worst cases, QOL remained unchanged. When patients wish, medication may be discontinued and surgical treatment may be chosen, provided that these patients are properly assisted and informed about the main side effect resulting from the surgical procedure, i.e. compensatory hyperhidrosis.

Based on analyses of the prognostic factors for improvement of QOL through treatment with oxybutynin, we found that there was no difference in evolution of quality of life compared with the levels of
QOL before treatment. Age, gender, and BMI were also unrelated to the patients' evolution.

We believe that in addition to the effectiveness presented, this therapeutic alternative is an excellent choice for the initial treatment of facial hyperhidrosis. Patients who choose this treatment have nothing to lose, and the least to be expected is that it will help prepare them to face sympathectomy in the future.

\section{CONCLUSIONS}

Treatment of facial hyperhidrosis with oxybutynin represents a good alternative to sympathectomy, since it produces good results and improves QOL. Moreover, patients do not face the risk of experiencing the side effects of sympathectomy. 


\section{REFERÊNCIAS}

1. Weber A, Heger S, Sinkgraven R, Heckmann M, Elsner P, Rzany B. Psychosocial aspects of patients with focal hyperhidrosis. Marked reduction of social phobia, anxiety and depression and increased quality of life after treatment with botulinum toxin A. Br J Dermatol. 2005:152:342-5.

2. Stolman LP. Treatment of hyperhidrosis. J Drugs Dermatol. 2003;2:521-7.

3. Kao MC, Chen YL, Lin JY, Hsieh CS, Tsai JC. Endoscopic sympathectomy treatment for craniofacial hyperhidrosis. Arch Surg. 1996;131:1091-4.

4. Lin TS, Fang HY. Transthoracic endoscopic sympathectomy for craniofacial hyperhidrosis: analysis of 46 cases. J Laparoendosc Adv Surg Tech A. 2000;10:243-7.

5. Kim DH, Paik HC, Lee DY. Comparative analysis of T2 selective division of rami-communicantes (ramicotomy) with T2 sympathetic clipping in the treatment of craniafacial hyperhidrosis. Eur J Cardiothorac Surg. 2004;26:396-400.

6. de Campos JR, Wolosker N, Takeda FR, Kauffman P, Kuzniec S, Jatene FB, et al. The body mass index and level of resection: predictive factors for compensatory sweating after sympathectomy. Clin Auton Res. 2005;15:116-20.

7. Wolosker N, Yazbek G, Ishy A, de Campos JR, Kauffman P, Puech-Leão P. Is sympathectomy at T4 level better than at T3 level for treating palmar hyperhidrosis? J Laparoendosc Adv Surg Tech A. 2008;18:102-6.

8. Ribas Milanez de Campos J, Kauffman P, Wolosker N, Munia MA, de Campos Werebe E, Andrade Filho LO, et al. Axillary hyperhidrosis: T3/T4 versus T4 thoracic sympathectomy in a series of 276 cases. J Laparoendosc Adv Surg Tech A. 2006;16:598-03.

9. Gossot D, Kabiri H, Caliandro R, Debrosse D, Girard P, Grunenwald D. Early complications of thoracic endoscopic sympathectomy: a prospective study of 940 procedures. Ann Thorac Surg. 2001;71:1116-9

10. Baumgartner FJ, Bertin S, Konecny J. Superiority of thoracoscopic sympathectomy over medical management for the palmoplantar subset of severe hyperhidrosis. Ann Vasc Surg. 2009;23:1-7.

11. Arisco A, Brantly E, Kraus S. Oxybutynin extended release for the management of overactive bladder: a clinical review. Drug Des Devel Ther. 2009;3:151-61.

12. Lefrandt JD, Maurer JM. Oxybutynin for hyperhidrosis. Neth J Med. 2007:65:356

13. Mijnhout GS, Kloosterman H, Simsek S, Strack van Schijndel RJ, Netelenbos JC. Oxybutynin: dry days for patients with hyperhidrosis. Neth J Med. 2006;64:326-8.

14. Schollhammer M, Misery L. Treatment of hyperhidrosis with oxybutynin. Arch Dermatol. 2007;143: 544-5.

15. Tupker RA, Harmsze AM, Deneer VH. Oxybutynin therapy for generalized hyperhidrosis. Arch Dermatol. 2006;142:1065-6.

16. Amir M, Arish A, Weinstein Y, Pfeffer M, Levy Y. Impairment in quality of life among patients seeking surgery for hyperhidrosis (excessive sweating): preliminary results. Isr J Psychiatry Relat Sci. 2000;37:25-31.

17. de Campos JR, Kauffman P, Werebe Ede C, Andrade Filho LO, Kusniek S, Wolosker $\mathrm{N}$, et al. Quality of life, before and after thoracic sympathectomy: report on 378 operated patients. Ann Thorac Surg. 2003;76:886-91.
18. Lin TS, Fang HY. Transthoracic endoscopic sympathectomy in the treatment of palmar hyperhidrosis--with emphasis on perioperative management (1,360 case analyses). Surg Neurol. 1999;52:453-7.

19. Gelbard CM, Epstein H, Hebert A. Primary pediatric hyperhidrosis: a review of current treatment options. Pediatr Dermatol. 2008;25:591-8.

20. Glaser DA, Hebert AA, Pariser DM, Solish N. Facial hyperhidrosis: best practice recommendations and special considerations. Cutis. 2007;79:29-32.

21. Araújo CA, Azevedo IM, Ferreira MA, Ferreira HP, Dantas JL, Medeiros AC Compensatory sweating after thoracoscopic sympathectomy: characteristics, prevalence and influence on patient satisfaction. J Bras Pneumol. 2009;35:213-20.

22. Nabi G, Cody JD, Ellis G, Herbison P, Hay-Smith J. Anticholinergic drugs versus placebo for overactive bladder syndrome in adults. Cochrane Database Syst Rev. 2006; CD003781.

23. Sayeed RA, Nyamekye I, Ghauri AS, Poskitt KR. Quality of life after transthoracic endoscopic sympathectomy for upper limb hyperhidrosis. Eur J Surg. 1998;580:39-42.

24. Lau WT, Lee JD, Dang CR, Lee L. Improvement in quality of life after bilateral transthoracic endoscopic sympathectomy for palmar hyperhidrosis. Hawaii Med J. 2001;60:126,137.

25. Wolosker N, Yazbek G, Milanez de Campos JR, Kauffman P, Ishy A, Puech-Leão P. Evaluation of plantar hyperhidrosis in patients undergoing video-assisted thoracoscopic sympathectomy. Clin Auton Res. 2007;17:172-6

26. Schmidt J, Bechara FG, Altmeyer P, Zirngibl H. Endoscopic thoracic sympathectomy for severe hyperhidrosis: impact of restrictive denervation on compensatory sweating. Ann Thorac Surg. 2006;81:1048-55.

27. Bachmann K, Standl N, Kaifi J, Busch P, Winkler E, Mann O, et al. Thoracoscopic sympathectomy for palmar and axillary hyperhidrosis: four-year outcome and quality of life after bilateral 5-mm dual port approach. Surg Endosc. 2009;23:1587-93.

ENDEREÇO PARA CORRESPONDÊNCIA / MAILING ADDRESS: Nelson Wolosker

Av. Albert Einstein, 627/701 - Morumbi

05652-000 São Paulo - SP

e-mail address:nwolosker@yahoo.com.br

Como citar este artigo/How to cite this article: Wolosker N, de Campos JRM, Kauffman P, Munia MA, Neves S, Jatene FB, Puech-Leão P. The use of oxybutynin for treating facial hyperhidrosis. An Bras Dermatol. 2011;86(3):451-6. 